\title{
ELECCIONES LEGISLATIVAS EN FRANCIA
}

Expirado el mandato de cinco años de la Asamblea Nacional, el electorado galo fue convocado a las urnas el 16 de marzo de 1986, para cubrir los 577 escaños de que consta actualmente la Cámara Baja del Parlamento francés, tras la reforma socialista de la Ley electoral en abril de 1985. Pese a la citada reforma, que sustituía el tradicional sistema mayoritario a dos vueltas por el proporcional, la oposición conservadora formada por el RPR (Reagrupamiento para la República) y la UDF (Unión para la Democracia Francesa) fue mayoritaria en dichos comicios.

La modificación del modelo electoral no favoreció a sus impulsores, sino que, al contrario, los resultados de las elecciones mostraron un sensible retroceso socialista (62 escaños menos que en 1981), a pesar de la campaña personal del Presidente de la República, F. Miterrand. Asimismo, el 16 de marzo, las urnas depararon al Partido Comunista francés un importante fracaso (nueve escaños menos que en 1981), y una preocupante y sorprendente ascensión de la extrema derecha que dirige Le Pen.

La victoria del centro-derecha, previsible ya con anterioridad a la campaña electoral como consecuencia de los errores de gobierno del Partido Socialista, creaba una delicada situación que se conoce con el nombre de "conflicto de mayorias", es decir, una inadecuación entre la mayoría presidencial y la mayoría parlamentaria, la cual puede provocar un parcial bloqueo de las instituciones.

Como es sabido, el mandato del Presidente de la República es de siete años, frente a los cinco de la Asamblea Nacional. De esta forma, y como consecuencia de la cercanía temporal con que se celebraron ambas elecciones en 1981, el mandato presidencial se prolonga dos años desde la elección de esta nueva Asamblea en 1986. 
CUADRO 1. COMPOSICION DE LA ASAMBLEA NACIONAL *

\begin{tabular}{lccc}
\hline \multicolumn{1}{c}{ PARTIDOS } & $\begin{array}{c}\text { VOTOS } \\
1986(\%)\end{array}$ & $\begin{array}{c}\text { ESCAÑOS } \\
1981\end{array}$ & $\begin{array}{c}\text { ESCAÑOS } \\
1986\end{array}$ \\
\hline Extrema Izquierda & 1,53 & - & - \\
Partido Comunista F. & 9,78 & 35 & 44 \\
Partido Socialista F. & 31,04 & 207 & 269 \\
Unión de la Izquierda & 0,20 & 2 & - \\
Radicales de Izquierda & 0,38 & 2 & 14 \\
Diversos Izquierda & 1,03 & 5 & 6 \\
Ecologistas & 1,21 & - & - \\
Regionalistas & 0,10 & - & - \\
RPR & 11,21 & 76 & 83 \\
UDF & 8,31 & 53 & 64 \\
RPR-UDF & 21,46 & 148 & - \\
Diversos Derecha & 3,90 & 14 & 8 \\
Frente Nacional & 9,65 & 35 & - \\
Extrema Derecha & 0,20 & - & - \\
\hline
\end{tabular}

CUADRO 2. NIVEL DE PARTICIPACION *

\begin{tabular}{lrlr}
\multicolumn{2}{c}{1986} & & \multicolumn{1}{l}{1981} \\
\hline Inscritos: & 37.541 .124 & Inscritos: & 35.204 .152 \\
Votantes: & 29.317 .729 & Votantes: & 29.141 .979 \\
& & & \\
Abstención (\%): & 21,99 & Abstención: & 17,23 \\
\hline
\end{tabular}

* Fuente; Embajada de Francia en Madrid.

El Presidente de la República se encontró, pues, el 16 de marzo pasado ante cuatro posibilidades, dada la mayoría parlamentaria conservadora. En primer término, el Presidente podía nombrar como Primer Ministro a un miembro de su partido, a quien sería, con toda seguridad, imposible llevar a cabo la función de gobierno, ya que precisaba para ello de la confianza de la Asamblea, de la cual no disponía. En segundo lugar, y dado que el Presidente de la República se comprometió personalmente durante la campaña electoral en favor del Partido Socialista, la llegada a la Asamblea Nacional de una mayoría hostil a su política, podia haberle llevado a dimitir. En tercer lugar, F. Mitterrand podia haber decretado sin refrendo la disolución de la nueva Cámara electa como medio de 
resolver sus diferencias con la mayoría parlamentaria. Pero la utilización de este mecanismo como un medio de intentar restablecer la armonía entre el poder presidencial y la Asamblea Nacional constituye un grave riesgo para el Presidente, porque si esa mayoría hostil a la política presidencial se confirma en las siguientes elecciones, al Jefe del Estado no le queda más remedio que pasar a un segundo plano, políticamente hablando, o dimitir.

Sin embargo, el Presidente Mitterrand eligió otra solución: la llamada "Cohabitación». Nada impedía al Presidente de la República escoger a su Primer Ministro entre la nueva mayoría, hostil a la mayoría presidencial. Se trata de un interesante juego de reequilibrio entre dos poderes. El problema, el grave problema, es que esta situación puede conducir, de hecho, a un callejón sin salida, ya que los actos más importantes del Gobierno requieren constitucionalmente el acuerdo del Presidente de la República, y los proyectos políticos e ideológicos de Mitterrand y Chirac, nuevo Primer Ministro, están condenados al enfrentamiento. Ambos proponen modelos de gestión de la cosa pública que no son siempre compatibles.

PILAR MELLADO PRADO 